\title{
Phycosphere associated bacteria; a prospective source of bioactive compounds
}

\author{
Sandhya Soolamkandath Variem ${ }^{1}$ (D) - Vijayan Koyadan Kizhakkedath ${ }^{2}$
}

Received: 31 July 2020 / Accepted: 23 October 2020 / Published online: 5 November 2020

(C) Institute of Molecular Biology, Slovak Academy of Sciences 2020

\begin{abstract}
Co-occurrence of bacteria and algae can be traced back to billions of years ago. Their coexistence for more than 200 million years in common habitat has fostered a multitude of promising interactions among these two groups over evolutionary time scales. These associated bacteria produce various biologically active secondary metabolites and play a pivotal role in algal growth and metabolism. Consequently, specific chemical microenvironment created by algal microbiome signifies a promising source of bioactive compounds. Although these associations may be of substantial importance, only limited knowledge on the chemical ecology of algal microhabitat is available. Thus, better insight into the metabolic capabilities of phycosphere microbiome could allow targeted isolation of novel bioactive compounds with manifold beneficial effects. Moreover, further research contributing towards the chemistry behind these interactions is needed for exploring phycosphere bacteria for desired industrial and biotechnological applications.
\end{abstract}

Keywords Phycosphere bacteria $\cdot$ Bioactive compounds · Algal-bacterial association $\cdot$ Secondary metabolites

Oceans, the largest biome on earth, harbour tremendous diversity of living microorganisms (Penesyan et al. 2010; Amin et al. 2012). It was estimated that oceans contribute nearly half of the global productivity which has been carried out by ubiquitous photoautotrophs referred to as marine algae (Geng and Belas 2010; Ramanan et al. 2016). The organic carbon produced by these photosynthetic organisms is further remineralised to $\mathrm{CO}_{2}$ by heterotrophic bacteria. Thus, bacteria play a pivotal role in converting ocean's primary productivity to dissolved organic matter (Geng and Belas 2010; Amin et al. 2012). Altogether, these ubiquitous populations drive marine biogeochemical cycles and thus ensure a balance in energy flow. Hence, these foremost functional entities together are considered structural pillars of the marine ecosystem (Natrah et al. 2014; Ramanan et al. 2016). Undoubtedly, this interorganism association plays a crucial role in shaping aquatic

Sandhya Soolamkandath Variem

sandhyavarier@gmail.com; sandhyasv@nio.org

1 Biological Oceanography Division, CSIR- National Institute of Oceanography, Goa 403 004, India

2 ICAR-Central Institute of Brackishwater Aquaculture, Tamil Nadu 600 028, India ecosystem function and has gained current research interest (Ramanan et al. 2016). The term 'Phycosphere' - the aquatic analogue of the rhizosphere, was coined in 1972 by Bell and Mitchell to define a zone that extends outward from an algal colony or cell for an undefined distance, in which growth of bacteria is enhanced by extracellular products of algae. Bacterial groups such as Gammaproteobacteria, Alphaproteobacteria, Actinobacteria, Betaproteobacteria, Bacilli and Bacteroidetes were most prominently found in the phycosphere of different algal groups (Nicolas et al. 2004; Sapp et al. 2007; Amin et al. 2012; Natrah et al. 2014). Many associated bacteria secrete numerous growth promoters which can improve the physiological state of the algal host (Croft et al. 2005; de-Bashan and Bashan 2008; Guo and Tong 2014). Simultaneously, algae excrete organic carbon compounds and other products that have a stimulatory effect on bacterial associates (Natrah et al. 2014). Algalbacterial interactions do not always have positive effects; rather, may have negative consequences. Active compounds released by many algicidal bacteria can lyse algal cells (Amin et al. 2012; Natrah et al. 2014). A summary of algal-bacterial interactions that exists in the phycosphere is depicted in Fig. 1.

It has been well proven that marine organisms, especially marine algae represent a vital source of fascinating bioactive compounds (Konig et al. 2006; Bai and Krishnakumar 2013). 
Fig. 1 A schematic summary of positive and negative interactions between algae and bacteria that exist in the phycosphere

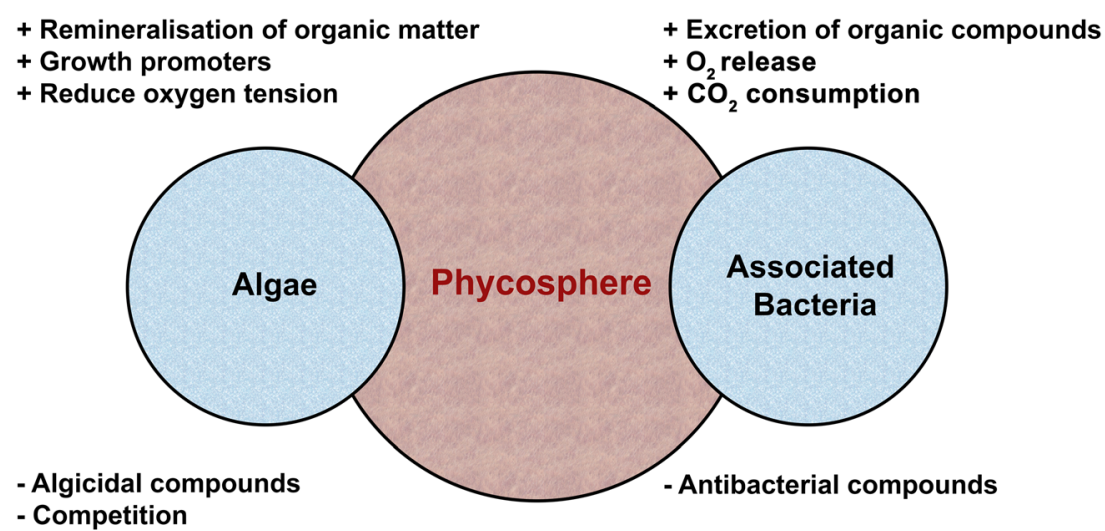

Upon recognition that most of the algal habitat harbor metabolically diverse bacterial counterparts, one of the most intriguing questions in marine bioprospecting is which partner organism produces which secondary metabolite (Konig et al. 2006; Penesyan et al. 2010). Moreover, many compounds, formerly ascribed to eukaryotic hosts, have later been proved to be produced by bacterial symbionts ( $\mathrm{Li}$ and Vederas 2009). Hence, bacterial richness in algal microhabitat opens up new avenues for the discovery of novel bioactive compounds. Bacterial symbionts construct chemical microenvironments with their algal host and contribute significantly to host evolution, performance and function (Penesyan et al. 2010). Algal growth stimulatory compounds released by associated bacteria include vitamins, essential minerals, polyunsaturated fatty acids, quorum sensing signaling molecules, auxins, carbohydrates and proteins (Krug et al. 2020; Zhang et al. 2020). Several algal species are incapable of synthesizing specific vitamins required for their growth (cobalamin, thiamin) and obtain these vitamins from their bacterial counterparts (Natrah et al. 2014). For example, the microalga Amphidinium operculatum obtain vitamin cobalamin from its bacterial associate Halomonas (Croft et al. 2005). Likewise, Ruegeria pomeroyi associated with the diatom Thalassiosira pseudonana secrete vitamin $\mathrm{B}_{12}$ in exchange for diatom derived organic carbon (Seymour et al. 2017). In addition, bacterial groups found in association with algae are reported to produce phytohormones (indole-3-acetic acid), siderophore and antibiotics (Villarreal-Gómez et al. 2010; Natrah et al. 2014; Lian et al. 2018). Previously, we reported that Labrenzia sp. Mab 26 associated with microalgae, Isochrysis galbana is capable of synthesizing both siderophore and indole-3-acetic acid (Sandhya and Vijayan 2019). Similarly, Marinobacter spp., one of the most predominant bacterial groups in diverse algal habitats could produce siderophore, vibrioferrin (Amin et al. 2012; Fuentes et al. 2016; Sandhya et al. 2017). Bioactive molecules produced by associated bacteria often contribute to algal defense mechanisms to fight with pathogens and other competitive predators (Paul et al. 2011; Balakrishnan et al. 2014). It was reported that bacterial populaces that reside in algal habitat produce toxins, signaling molecule and other secondary metabolites as their inhibitory traits (Kizhakkekalam and Chakraborty 2020). These bacterial defense communities make the phycosphere a potential reservoir of new antibiotics, drug molecules and pharmaceutical agents. For instance, Phaeobacter gallaeciensis, the bacterial associate of Emiliania huxleyi could produce tropodithietic acid, a broad-spectrum antibiotic (Lian et al. 2018). The heterotrophic bacteria associated with brown algae Sargassum sp. and red marine macroalgae Ceratodyction spongiosum were reported to inhibit pathogenic methicillin resistant Staphylococcus aureus (Isnansetyo et al. 2001; Susilowati et al. 2015). Moreover, a study conducted by Kizhakkekalam and Chakraborty (2019) recognized macroalgae associated Bacillus amyloliquefaciens as a potent candidate to develop products with broad biotechnological and therapeutic applications. Additionally, the antioxidant production potential of heterotrophic bacteria associated with I. galbana has also been reported (Sandhya and Vijayan 2019).

Motone et al. 2020 showed that antioxidant carotenoid produced by a bacterial symbiont could mitigate light and thermal stresses in cultured Symbiodiniaceae algae, isolated from coral reef, Galaxea fascicularis. Such metabolic potential of symbiotic bacteria could open up novel approaches toward coral protection from environmental stress. Likewise, Fradinho et al. (2013) demonstrated successful production of polyhydroxyalkanoates (a green alternative to plastic) using a consortium of algae and bacteria. Finally, the phycosphere of several seaweed species harbour metabolically versatile bacterial associates capable of producing anticancer substances, polysaccharides, bacteriocines, protease, lysozymes and organic acids (Soria-Mercado et al. 2012). These metabolic or chemical based interactions clearly emphasize the significance of phycosphere bacteria as an epitome source of bioactive compounds. However, to date, biotechnological potential of phycosphere bacteria is largely unexplored. Difficulties in isolation and cultivating these bacterial symbionts represent a key bottleneck in their exploitation. One of the successful 
strategies to boost up culturability of bacterial symbionts is to mimic conditions of their natural habitat. Such manipulation of physical and chemical growth parameters may help to obtain maximum yield of desired metabolites (Penesyan et al. 2010). Advent of genome sequencing technologies such as metagenomics and next generation sequencing could provide better insight into the diversity of the phycosphere microbiome. Additionally, other omics methodologies including proteomics, metabolomics and transcriptomics could further elucidate the functional aspects and ecological implications of various metabolites synthesised by these bacterial communities (Zhang et al. 2020). For instance, Cooper and Smith (2015) deciphered thiamine biosynthetic pathways of the bacterium Pseudoalteromonas sp. TW7 in Ostreococcus tauri co-culture using transcriptomes analysis. Thus, functional metagenomics approaches along with suitable culturing conditions would certainly trigger additional studies and the pursuit for unique bioactive compounds. Design of a "bacterial consortium" is another promising horizon for industrial microbiology. A consortium of bacteria can carry out various complex functions that are impossible for a single bacterium (Bhatia et al. 2018). Hence, in-depth understanding of algalbacterial interaction using advanced functional genomic tools is critical to facilitate the construction of novel consortia of phycosphere bacteria with broad spectrum applications.

Overall, a close and strong association occur between marine algae and bacteria which make the phycosphere a hotspot for the exchange of numerous chemical currencies. The interactions between algae and bacteria are primarily controlled by the chemical characteristics of these exchanged mediator molecules including growth resources and other infochemicals. Thus, unravelling algal-bacterial interactions provide new perspectives on utilizing such knowledge in search of diverse bioactive compounds. Moreover, further research focusing on the microbiological and chemical features of phycosphere will ultimately have a great impact on the biotechnological and pharmaceutical industry.

Acknowledgements We are indebted to Dr. Sunil Kumar Singh, the Director, CSIR-National Institute of Oceanography, Goa for his active support. We thank Dr. Julia M. Novak Colwell, Lecturer, Department of Natural Resources \& the Environment, University of New Hampshire for her editorial support. CSIR-NIO contribution No. is 6625.

\section{Compliance with ethical standards}

Conflict of interest The authors declare that they have no potential conflict of interest.

\section{References}

Amin SA, Parker MS, Armbrust EV (2012) Interactions between diatoms and bacteria. Microbiol Mol Biol Rev 76: 667-684. https://doi.org/ 10.1128/MMBR.00007-12
Bai VDM, Krishnakumar S (2013) Evaluation of antimicrobial metabolites from marine microalgae Tetraselmis suecica using gas chromatography - mass spectrometry (GC - MS) analysis. Int J Pharm Pharm Sci 5:17-23

Balakrishnan D, Kandasamy D, Nithyanand P (2014) A review on antioxidant activity of marine organisms. Int J ChemTech Res 6(7): 3431-3436

Bell W, Mitchell R (1972) Chemotactic and growth responses of marine bacteria to algal extracellular products. Biol Bull 143:265-277. https://doi.org/10.2307/1540052

Bhatia SK, Bhatia RK, Choi YK, Kan E, Kim YG, Yang YH (2018) Biotechnological potential of microbial consortia and future perspectives. Crit Rev Biotechnol 38(8):1209-1229. https://doi.org/ $10.1080 / 07388551.2018 .1471445$

Cooper MB, Smith AG (2015) Exploring mutualistic interactions between microalgae and bacteria in the omics age. Curr Opin Plant Biol 26:147-153. https://doi.org/10.1016/j.pbi.2015.07.003

Croft MT, Lawrence AD, Raux-Deery E, Warren MJ, Smith AG (2005) Algae acquire vitamin $\mathrm{B}_{12}$ through a symbiotic relationship with bacteria. Nature 438:90-93. https://doi.org/10.1038/nature04056

de-Bashan LE, Bashan Y (2008) Joint immobilization of plant- growth promoting bacteria and green microalgae in alginate beads a an experimental model for studying plant-bacterium interactions. Appl Environ Microbiol 74:6797 - 6802. https://doi.org/10.1128/ aem.00518-08

Fradinho JC, Domingos JMB, Carvalho G, Oehmen A, Reis MAM (2013) Polyhydroxyalkanoates production by a mixed photosynthetic consortium of bacteria and algae. Bioresour Technol 132:146153. https://doi.org/10.1016/j.biortech.2013.01.050

Fuentes JL, Garbayo I, Cuaresma M, Montero Z, González-Del-Valle M, Vílchez C (2016) Impact of microalgae-bacteria interactions on the production of algal biomass and associated compounds. Mar Drugs 14: 100. https://doi.org/10.3390/md14050100

Geng H, Belas R (2010) Molecular mechanisms underlying Roseobacter - phytoplankton symbioses. Curr Opin Biotechnol 21:332-338. https://doi.org/10.1016/j.copbio.2010.03.013

Guo Z, Tong YW (2014) The interactions between Chlorella vulgaris and algal symbiotic bacteria under photoautotrophic and photoheterotrophic conditions. J Appl Phycol 26:1483-1492. https://doi.org/10.1007/s10811-013-0186-1

Isnansetyo A, Horikawa M, Kamei Y (2001) In vitro anti-methicillin resistant Staphylococcus aureus activity of 2,4diacetylphloroglucinol produced by Pseudomonas sp. AMSN isolated from a marine alga. J Antimicrob Chemother 47:724-725. https://doi.org/10.1093/oxfordjournals.jac.a002694

Kizhakkekalam VK, Chakraborty K (2019) Pharmacological properties of marine macroalgae associated heterotrophic bacteria. Arch Microbiol 201:505-518. https://doi.org/10.1007/s00203-018-15921

Kizhakkekalam VK, Chakraborty K (2020) Marine macroalgaeassociated heterotrophic Firmicutes and Gamma-proteobacteria: prospective anti-infective agents against multidrug resistant pathogens. Arch Microbiol 202:905-920. https://doi.org/10.1007/ s00203-019-01800-2

Konig GM, Kehraus S, Seibert SF, Abdel-Lateff A, Muller D (2006) Natural products from marine organisms and their associated microbes. Chem Bio Chem 7:229-238. https://doi.org/10.1002/cbic. 200500087

Krug L, Morauf C, Donat C, Müller H, Cernava T, Berg G (2020) Plant growth-promoting Methylobacteria selectively increase the biomass of biotechnologically relevant microalgae. Front Microbiol 11:427. https://doi.org/10.3389/fmicb.2020.00427

Li JW, Vederas JC (2009) Drug discovery and natural products: end of an era or an endless frontier? Science 325:161-165. https://doi.org/10. $1126 /$ science. 1168243 
Lian J, Wijffels RH, Smidt H, Sipkema D (2018) The effect of the algal microbiome on industrial production of microalgae. Microb Biotechnol 11(5): 806-818. https://doi.org/10.1111/1751-7915. 13296

Motone K, Takagi T, Aburaya S, Miura N, Aoki W, Ueda M (2020) A zeaxanthin producing bacterium isolated from the algal phycosphere protects coral endosymbionts from environmental stress. mBio 11: e01019-e01019. https://doi.org/10.1128/mBio.01019-19

Natrah FMI, Bossier P, Sorgeloos P, Yusoff FM, Defoirdt T (2014) Significance of microalgal-bacterial interactions for aquaculture. Rev Aquacult 6:48-61. https://doi.org/10.1111/raq.12024

Nicolas JL, Corre S, Cochard JC (2004) Bacterial population association with phytoplankton cultured in a bivalve hatchery. Microb Ecol 48: 400-413. https://doi.org/10.1007/s00248-003-2031-6

Paul VJ, Ritson-Williams R, Sharp K (2011) Marine chemical ecology in benthic environments. Nat Prod Rep 28:345-387. https://doi.org/10. 1039/C0NP00040J

Penesyan A, Kjelleberg S, Egan S (2010) Development of novel drugs from marine surface associated microorganisms. Mar Drugs 8:438459. https://doi.org/10.3390/md8030438

Ramanan R, Kim BH, Cho DH, Oh HM, Kim HS (2016) Algae-bacteria interactions: evolution, ecology and emerging applications. Biotechnol Adv 34:14-29. https://doi.org/10.1016/j.biotechadv. 2015.12.003

Sandhya SV, Vijayan KK (2019) Symbiotic association among marine microalgae and bacterial flora: a study with special reference to commercially important Isochrysis galbana culture. J Appl Phycol 31:2259-2266. https://doi.org/10.1007/s10811-019-01772-2

Sandhya SV, Preetha K, Nair AV, Antony ML, Vijayan KK (2017) Isolation, characterisation and phylogenetic diversity of culturable bacteria associated with marine microalgae from saline habitats of south India. Aquat Microb Ecol 79:21-30. https://doi.org/10.3354/ AME01815

Sapp M, Schwaderer AS, Wiltshire KH, Hoppe HG, Gerdts G, Wichels A (2007) Species-specific bacterial communities in the phycosphere of microalgae? Microb Ecol 53:683-699. https://doi.org/10.1007/ s00248-006-9162-5

Seymour JR, Amin SA, Raina JB, Stocker R (2017) Zooming in on the phycosphere: the ecological interface for phytoplankton-bacteria relationships. Nat Microbiol 2:17065. https://doi.org/10.1038/ nmicrobiol.2017.65

Soria-Mercado IE, Villarreal-Gómez LJ, Rivas GG, Sánchez NEA (2012) Bioactive compounds from bacteria associated to marine algae. In: Sammour R (ed) Biotechnology - molecular studies and novel applications for improved quality of human life, pp 25-44. https://doi. org $/ 10.5772 / 27842$

Susilowati R, Sabdono A, Widowati I (2015) Isolation and characterization of bacteria associated with brown algae Sargassum spp. from Panjang Island and their antibacterial activities. Procedia Environ Sci 23:240-246. https://doi.org/10.1016/j.proenv.2015.01.036

Villarreal-Gómez LJ, Soria-Mercado IE, Guerra-Rivas G, Ayala-Sánchez NE (2010) Antibacterial and anticancer activity of seaweeds and bacteria associated with their surface. Rev Biol Mar Oceanogr 45: 267-275. https://doi.org/10.4067/S0718-19572010000200008

Zhang B, Li W, Guo Y, Zhang Z, Shi W, Cui F, Lens PNL, Tay JH (2020) Microalgal-bacterial consortia: From interspecies interactions to biotechnological applications. Renew Sust Energ Rev 118: 109563. https://doi.org/10.1016/j.rser.2019.109563 